\title{
Periodical structures, absorption spectra and dichroism induced by laser radiation in composite $\mathrm{AgCl}-\mathrm{Ag}$ film
}

\author{
L.A.Ageev, V.K.Miloslavsky, V.I.Lymar, V.M.Reznikova \\ V.Karazin Kharkiv National University, Physics Department, \\ 4 Svobody Sq., 61022 Kharkiv, Ukraine
}

Received April 09, 2013

It has been demonstrated that linearly polarized $\left(\mathbf{E}_{0}\right)$ laser beam $(\lambda=445 \mathrm{~nm})$ brings on the photoinduced transformations in $\mathrm{AgCl}-\mathrm{Ag}$ composition, consisting of thin waveguide $\mathrm{AgCl}$ film on the glass and covered by $\mathrm{Ag}$ nanoparticles layer. Before the laser irradiation the sample has an absorption band related to localized plasmons in nanoparticles. Laser radiation excites plasmons and leads to waveguide $\mathrm{TE}_{0}$-modes scattering. Periodical structure develops under modes interference with the incident wave. Its scratches are formed by $\mathrm{Ag}$ particles and aligned with $\mathbf{E}_{0}$ predominantly. Measured by means of diffraction structure period $(291 \mathrm{~nm})$ is coincident with a value calculated using $\mathrm{TE}_{0}$-mode dispersion equation. A linear dichroism in absorption and a spectral drop (at $\lambda \approx 445 \mathrm{~nm}$ ) in the $\mathbf{E} / / \mathrm{E}_{0}$-polarized absorption spectrum are revealed. It is shown that the structures remain on the glass substrate after $\mathrm{AgCl}$ removal by means of a fixing agent. The dichroism value and its dispersion are modified after the fixing.

Показано, что линейно поляризованный $\left(\mathbf{E}_{0}\right)$ лазерный пучок $(\lambda=445 \mathrm{~nm})$ приводит к фотоиндуцированным превращениям в композиции $\mathrm{AgCl}-\mathrm{Ag}$, состоящей из тонкой волноводной пленки $\mathrm{AgCl}$ на стекле, покрытой слоем наночастиц $\mathrm{Ag}$. До облучения образец имеет полосу поглощения, связанную с локализованными плазмонами в наночастицах. Облучение возбуждает плазмоны и приводит к рассеянию волноводных $\mathrm{TE}_{0}$-мод. При интерференции мод с падающим пучком развивается периодическая структура, штрихи которой образованы частицами $\mathrm{Ag}$ и направлены преимущественно вдоль $\mathbf{E}_{0}$. Измеренный по дифракции период структуры (291 нм) совпадает с вычисленным из дисперсионного уравнения для $\mathrm{TE}_{0}$-моды. В поглощении обнаружен дихроизм и спектральный провал (при $\lambda \approx 445$ нм) для спектра, измеренного в поляризации $\mathbf{E} / / \mathbf{E}_{0}$. Показано, что структуры сохраняются на подложке после удаления $\mathrm{AgCl}$ в фиксаже, но величина и дисперсия дихроизма при этом изменяются.

Періодичні структури, спектри поглинання, дихроїзм, індуковані у композитній плівиі AgCl-Ag лазерним пучком. Л.О.Агєєв, В.К.Милославський, В.І.Лимар, B.М.Рєзнікова .

Показано, що лінійно поляризованний $\left(\mathbf{E}_{0}\right)$ лазерний пучок ( $\lambda=445$ нм) приводить до фотоіндукованих перетворювань у композиції $\mathrm{AgCl}-\mathrm{Ag}$, яка складається із тонкої хвилеводної плівки $\mathrm{AgCl}$ на склі з покриттям поверхні $\mathrm{AgCl}$ шаром наночастинок $\mathrm{Ag}$. До опромінення зразок має смугу поглинання, яка пов'язана 3 локалізованими плазмонами у наночастинках. Опромінення збуждує плазмони і приводить до розсіяння хвилеводних $\mathrm{TE}_{0}$-мод. При інтерференції мод 3 пучком, що падає, розвивається періодична структура, штрихи якої створені частинками Ag i спрямовані переважно вздовж $\mathbf{E}_{0}$. Виміряний за дифракцією період структури (291 нм) співпадає з розрахованим із дисперсійного рівняння для $\mathrm{TE}_{0}$-моди. У поглинанні виявлений дихроїзм $\mathrm{i}$ спектральний провал (при $\lambda \approx 445$ нм) для спектра, який виміряний у поляризації $\mathbf{E} / / \mathbf{E}_{0}$. Показано, що структури зберігаються на підкладці після видалення $\mathrm{AgCl}$ за допомогою фіксажу, однак величина і дисперсія дихроїзму при цьому змінюється. 


\section{Introduction}

New properties related to the quantum and classical size effects are found in nanoscaled objects. The light excitation of localized plasmons in small metal particles is a famous classical effect example [1]. Ones of the objects, interesting to study optical properties, are metal-dielectric compositions wherein metal forms ordered two-dimensional nanostructures on a dielectric planar waveguide surface [2-4]. These structures are created artificially by electron lithography methods [2] and can be treated as an example of metamaterials [3,4] with photon crystal properties in 2D (netlike) or 1D (diffraction grating) geometry. The main feature of these composites is an ability of light to excite plasmons in nanostructured metal and in doing so plasmon energy can be transmitted to dielectric waveguide modes.

It was previously shown that photosensitive $\mathrm{AgCl}-\mathrm{Ag}$ composition has similar properties. It is created by vacuum thin film deposition of polycrystalline $\mathrm{AgCl}$ on a glass substrate and then islet $\mathrm{Ag}$ film is deposited on $\mathrm{AgCl}$ surface [5]. In the present paper, $\mathrm{AgCl}-\mathrm{Ag}$ films properties are described. The blue semiconductor linearly polarized laser beam at $\lambda=445 \mathrm{~nm}$ was firstly used to irradiate films. It is shown that consisting of Ag nanoparticles periodical structures (PS) are formed in the film as a result of its irradiation; induced by the laser light transformations of film absorption spectrum have been studied.

\section{AgCl-Ag films preparation and their properties}

The films were prepared by thermal vacuum deposition on a dielectric substrate. A substance with a density $\rho$ of mass $M$ is evaporated completely from a flat evaporator (molybdenum) at a given distance $r$ to the substrate. The mass thickness $h$ of the deposited film is close to value calculated by the following [6]:

$$
h=\frac{M}{\pi \cdot \rho \cdot r^{2}} .
$$

In the paper AgCl films $(h \approx 30 \mathrm{~nm})$ on a glass, coated with islet $\mathrm{Ag}$ layer $(\approx 8 \mathrm{~nm})$, have been examined. The sample scheme after preparation is shown in Fig. 1a. It is assumed that fine Ag particles (small points below the upper interface of polycrystalline $\mathrm{AgCl}$ ) can penetrate into $\mathrm{AgCl}$ matrix during

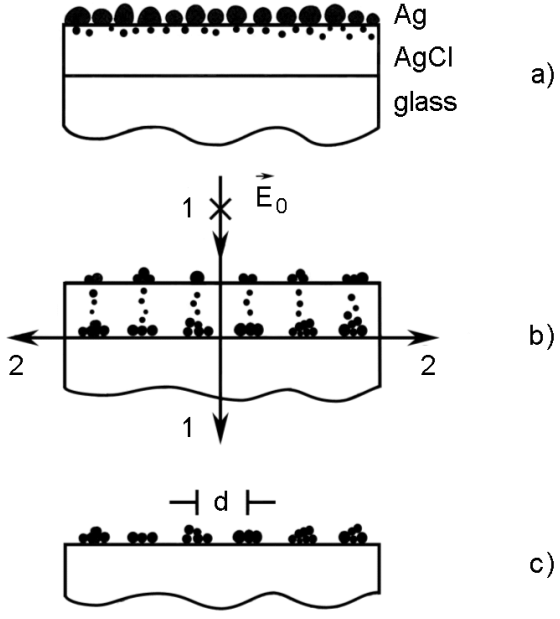

Fig. 1. Structural transformations scheme in $\mathrm{AgCl}-\mathrm{Ag}$. a) - before irradiation sample; b) - structural transformations at linearly polarized monochromatic beam irradiation (beam direction is shown by arrow $1 ; \times-$ beam polarization $\mathbf{E}_{0}$ direction is perpendicular to the figure plane, 2 - diffracted by PS beam; c) - after fixing sample, $d-\mathrm{PS}$ period.

the deposition process because of the thermal diffusion.

$\mathrm{AgCl}$ films are transparent in all visible spectrum range. Associated with silver the light absorption in AgCl-Ag system defines direct photosensitivity of the composition to the intense light action [5]. The electron-ion Ag mass transfer mechanism is supposed to take place in polycrystalline $\mathrm{AgCl}$ matrix under irradiation, similar to well known Mott-Gurney mechanism [7]. Plasmons are excited in Ag particles, giving rise to intrinsic photoelectric effect with further capture of photoelectrons inside $\mathrm{AgCl}$ matrix, and highly mobile $\mathrm{Ag}^{+}$ions are produced. These processes destroy initial Ag granules. New Ag particles are created in the light field minima as a result of the electrons capture by deep traps in $\mathrm{AgCl}$ and neutralization of coming to traps $\mathrm{Ag}^{+}$ions. It is assumed that the concentration of the effective traps is extremely high at film-substrate interface, and therefore owing to the light influence there is $\mathrm{Ag}$ transfer mainly from upper $\mathrm{AgCl}$ film surface to the substrate (Fig. 1b).

The above processes lead to $\mathrm{Ag}$ mass transfer and its redistribution in $\mathrm{AgCl}$ film. In this case photosensitivity persists, and an intensive light will lead to new Ag distribution at the changing of the irradiation conditions. At the same time, the photosen- 
sitivity to the direct light action is not very high. It becomes noticeable at exposures $H \sim 0.1 \div 1 \mathrm{~J} / \mathrm{cm}^{2}$. Optical film properties are changed very slowly under the action of common ambient light and it is not obligingly to defend the samples from routine exposure.

$\mathrm{AgCl}$ film on a glass substrate exhibits asymmetric planar waveguide properties [8] and it still stands in $\mathrm{AgCl}-\mathrm{Ag}$ system. Waveguide modes are generated inside $\mathrm{AgCl}$ film initially due to Rayleigh scattering and their interference with incident wave occurs. Silver is transferred to the interference minima and further modes are enhanced by a positive feedback mechanism. Silver has an effect on the waveguide properties and time evolution of the mode effective refractive index $n_{e f}=n \cdot \sin \theta \quad(n-$ film's refractive index, $\theta-$ the incidence angle of mode forming zigzag rays on the film boundaries) takes place in the process of photostructural transformations. Silver accumulates in the minima at saturation and $n_{e f}$ value is turned to be very close to the same of pure $\mathrm{AgCl}$ film at the wavelength $\lambda$ of an incident wave.

Interference leads to a periodic silver distribution. Waveguide modes scattering is isotropic in $\mathrm{AgCl}$ film under the action of nonpolarized or circularly polarized monochromatic light, and irregular periodical 2D grid of Ag particles is created [9]. At linear $\mathbf{E}_{0}$ incident wave polarization the mode scattering perpendicular to $\mathbf{E}_{0}$ dominates, and 1D periodical structures with their preferred wave vectors $\mathbf{K} \perp \mathbf{E}_{0}$ orientations are formed (Fig. 1b). The PS diffraction properties are similar to those of thin diffraction gratings.

After laser exposure $\mathrm{AgCl}$ has been dissolved by the photographic fixer (aqueous hyposulphite solution). In this case, settled on substrate under irradiation silver is left in place and hence the PS is still retained also (Fig. 1c). Relatively small fraction of $\mathrm{Ag}$ is washed away at the fixing procedure with $\mathrm{AgCl}-\mathrm{Ag}$. After fixing the sample is washed with water, dried and used to study PS diffraction properties by means of the laser beams as well as to observe the structure by an electron microscope. The fixing allows to prepare samples for electron microscopy to obtain silver structure images both on $\mathrm{AgCl}$ surface [10], and on the substrate [11]. Structures micrographs were obtained using PEM-125K electron microscope and are shown in Fig. 2a,b.

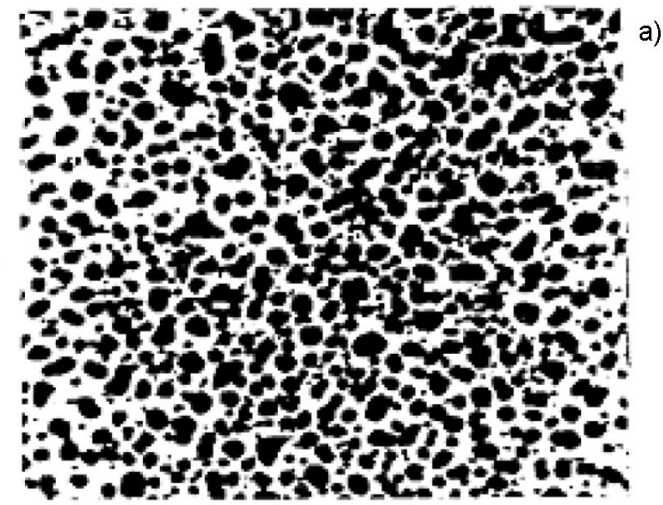

$0.5 \mu \mathrm{m}$

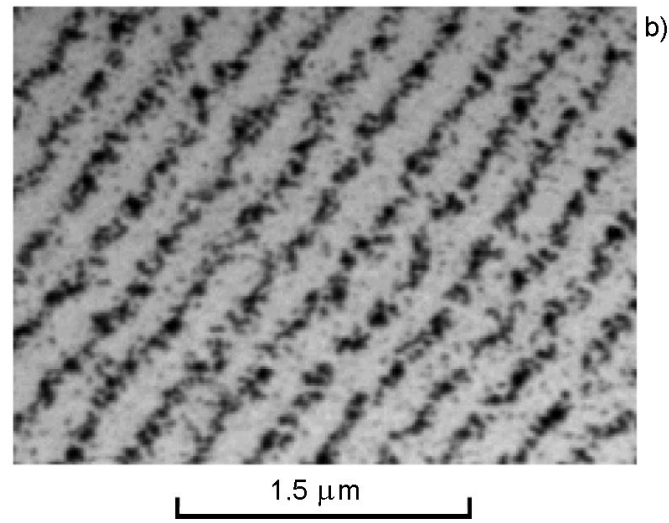

Fig. 2. Electron micrographs. a) - structure of $\mathrm{Ag}$ film deposited on $\mathrm{AgCl}$ film surface, that corresponds to the scheme of Fig. 1a; b) - PS on the substrate surface, that corresponds to the scheme of Fig. 1c.

\section{Results and discussion}

Blue linearly polarized semiconductor laser beam $(\lambda=445 \mathrm{~nm})$ has been used to irradiate $\mathrm{AgCl}-\mathrm{Ag}$ films at normal incidence. Continuous laser beam power was $P \approx 150 \mathrm{~mW}$. Beam cross section value was about $4.5 \mathrm{~mm}$ on the irradiated film. Exposure time was $t \approx 5 \mathrm{~min}$. In multimode films the PS can develop because of the excitation both $\mathrm{TE}_{m}$ and $T M_{m}$ waveguide modes [5]. For each of the excited modes the PS period $d$ has to be equal to $d=\lambda / n_{\text {ef }}$ at normal laser beam incidence. Varying waveguide film thickness value $h$ it is possible to vary $n_{\text {ef }}$ value over the range, which is determined by the values of substrate $n_{s}$ and film $n$ refractive indexes: $n_{s} \leq n_{e f}<n$ (at $n>n_{s}$ ). The lowest value $n_{e f}=n_{s}$ is realized if waveguide mode energy flux is localized mainly near waveguide-substrate interface. It is the case that is treated in our experiment with waveguide film thickness 
$h \leq h_{0}$, here $h_{0}-\mathrm{TE}_{0}$-mode cut-off thickness:

$$
h_{0}=\frac{\lambda}{2 \pi \sqrt{n^{2}-n_{s}^{2}}}\left(\operatorname{arctg} \sqrt{\frac{n_{s}^{2}-1}{n^{2}-n_{s}^{2}}}\right) .
$$

In doing so PS development is determined by $\mathrm{TE}_{0}$-mode excitation only, other waveguide modes can not be excited because their cut-off thicknesses are substantially more. According to (2) at $\lambda=445 \mathrm{~nm}$ and using reference values of $n=2.10(\mathrm{AgCl})$ and $n_{s}=1.53$ (K8 glass) it results $h_{0}=$ $33 \mathrm{~nm}>h \approx 30 \mathrm{~nm}$ (calculated by using (1)) and at $n_{e f}=n_{s}$ PS has the period $d=291 \mathrm{~nm}$.

The incident beam is diffracting as the PS develops during irradiation. Diffracted wave is a superposition of the waveguide modes, which define the PS growth, and the substrate modes. At inducing beam normal incidence it is fulfilled the following diffraction condition:

$$
k_{d}= \pm K
$$

here $k_{d}$ - the tangential wave vector component of the diffracted wave, $k_{d}=$ $(2 \pi / \lambda) \cdot n_{e f}$ in the case of diffracted waveguide modes and $k_{d}=(2 \pi / \lambda) n_{s} \cdot \sin \varphi_{d}$ in the case of diffracted substrate modes, $\varphi_{d}-$ a diffraction angle; $K=2 \pi / d=$ $(2 \pi / \lambda) n_{e f}$ - the tangential wave vector component of the growing on waveguide modes. If $n_{e f}=n_{s}$ is realized then it follows from (3) that diffraction occurs at angles $\varphi_{d}= \pm \pi / 2$ into substrate, providing symmetrical beams along the film-substrate interface. These beams can be observed as exiting ones through the substrate ends (beams 2 in Fig. 1b). Their appearance testifies to waveguide layer thickness correspondence to made by using (1) estimation. Saturation in the intensity growth of just mentioned diffracted beams defines the exposure time value given above.

The PS period $d$ is conveniently determined by means of an autocollimation method. An autocollimation angle $\varphi_{a}$ is measured wherein diffracted by the PS light is exactly directed to meet the incident beam. In doing so period $d$ value is calculated using the formula:

$$
d=\frac{\lambda}{2 \sin \varphi_{a}}
$$

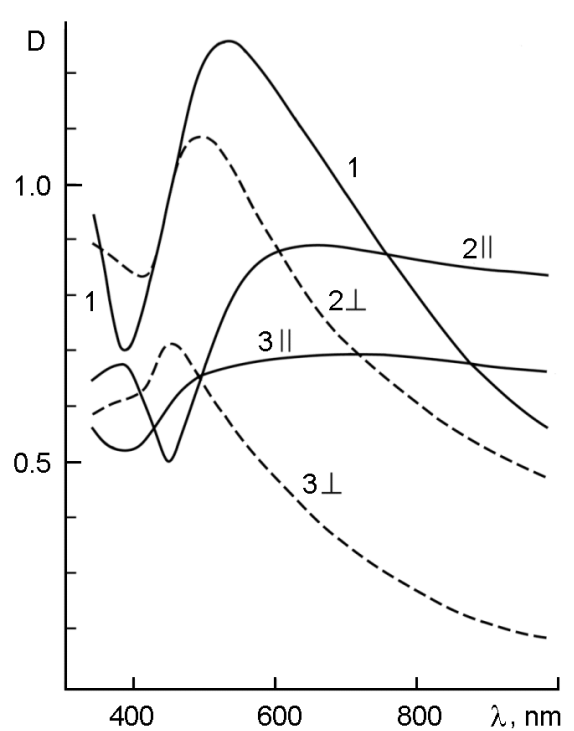

Fig. 3. Optical density spectra. 1 - before irradiation sample, 2 - after irradiation sample, 3 - after fixing sample, icons $/ /, \perp$ indicate measuring beam polarization $\mathbf{E} / / \mathbf{E}_{0}$ and $\mathbf{E} \perp \mathbf{E}_{0}$, respectively.

$\mathrm{AgCl}-\mathrm{Ag}$ reversibility has to be taken into account at diffraction measurement process. The photosensitivity of the irradiated spot persists after exposure, hence the structure is gradually rebuilding if laser beam incidence angle has been changed. But after fixing the sample loses its photosensitivity and it may be kept arbitrarily long under the measuring beam action. Period $d$ measurements were carried out both before and after the fixing using the laser beam at $\lambda=445 \mathrm{~nm}$ and gave $d \approx 291 \pm 0.3 \mathrm{~nm}$, which is in agreement with the above calculated value.

Transmission spectra in the wavelength range of $340 \div 1000 \mathrm{~nm}$ were measured relative to a clean substrate by means of SF-26 spectrophotometer. Measurements were performed in polarized light on laser irradiated samples using Glan-Thompson polarizing prism mounted after SF-26 exit slit. Results as optical density dependences $D(\lambda)=-\ln T(\lambda)$ are shown in Fig. 3. The spectrum of the unirradiated sample is presented by the curve 1 . Sample absorption is caused by silver only, an interference can be ignored because of the absorption and small film thickness. Therefore it is useful to compare the measured spectrum with that one, which would have a "free solid" Ag film of $h=8 \mathrm{~nm}$ thickness. It can be obtained using reference data on $\mathrm{Ag}$ absorption index $\chi$ dispersion [12]. The calculation $D=4 \pi \chi h / \lambda$ gives 
a minimum $\left(D_{\min } \approx 0.1\right)$ at $\lambda_{\min } \approx 320 \mathrm{~nm}$, then the growth of $D$ at $320<\lambda<400 \mathrm{~nm}$. Further, in the range of $\lambda=400 \div 1000 \mathrm{~nm}$, $D$ is increasing slowly in the limits of $D \approx 0.5 \div 0.7$. Wavelength value $\lambda_{\text {min }}$ corresponds to known Ag threshold frequency $\omega_{\min } \approx 5.9 \cdot 10^{15} \mathrm{~s}^{-1}$, above which the absorption is caused by interband transitions.

The main difference between the measured spectrum 1 and calculated one for "free solid" Ag film is the presence of asymmetric absorption band with a maximum at $\lambda=528 \mathrm{~nm}$. Minimum of the measured spectrum $(\lambda \approx 386 \mathrm{~nm})$ is not coincident with just mentioned "free solid" $\lambda_{\text {min }}$, but we suggest that it is connected with interband transitions influence on the shortwave slope of the measured spectrum 1 .

Spectrum 1 absorption band should be associated with localized plasmons excitation in Ag nanoparticles (Fig. 2a). It can be seen that the particles have similar to a sphere shape. There is a wide spread in the particles sizes. An average radius estimation gives $R \approx 20 \mathrm{~nm}$. The smallest particles have $R \approx 5 \mathrm{~nm}$.

It is the smallest particles that have to give the sharpest plasma resonance. For isolated silver particles completely surrounded by $\mathrm{AgCl}$, which do not interact with each other, the absorption maximum is observed at Frohlich frequency [5, 13]:

$$
\omega_{F}=\frac{\omega_{p}}{\sqrt{\varepsilon_{m}+2 \varepsilon_{0}}},
$$

here $\omega_{p}-$ the plasma frequency $\left(\omega_{p} \approx 13.3 \cdot 10^{15} \mathrm{~s}^{-1}\right.$ for $\left.\mathrm{Ag}\right) ; \varepsilon_{m} \approx 4$ (at $\lambda>\lambda_{\text {min }}$ ) - the interband transitions input to $\mathrm{Ag}$ dielectric constant value [14]; $\varepsilon_{0} \approx 4.4-\mathrm{AgCl}$ dielectric constant. Using these data $\omega_{F} \approx 3.7 \cdot 10^{15} \mathrm{~s}^{-1}$, that is close to the maximum of the curve 1: $\omega_{\max } \approx 3.6 \cdot 10^{15} \mathrm{~s}^{-1}$. This result allows to assume that during $\mathrm{Ag}$ deposition its fine particles are formed not only on $\mathrm{AgCl}$ surface (Fig. 1a; 2a), but also penetrate by diffusion into near-surface AgCl layer (Fig. 1a).

The quantities in (5) are known with moderate accuracy. As a rule, resonance frequencies and spectra calculations are associated with the necessity to choose and adjust many parameters (size, shape, relative particles position, absorption bands shape and width, etc.), so only a qualitative discussion of the spectra is given in the following.

Polarized $2 \perp, / /$ spectra in Fig. 3 were measured after laser irradiation of the film and the PS had formed in it. Spectra $3 \perp$,// were measured after the fixing of the same film. The measurements were performed using two polarizations: $\mathbf{E} \perp \mathbf{E}_{0}$ and $\mathbf{E} \| \mathbf{E}_{0}$, i.e. at the orientations of the measuring beam polarization $\mathbf{E}$ perpendicular and parallel to the PS scratches direction (Fig. 2b).

By the dispersion behavior curves $2 \perp$ and $3 \perp$ are similar to curve 1 on the long-wave slopes, but $D$ magnitude is decreased. Shortwave segments are essentially different. Maxima positions are not strictly described by the formula (5). The most significant $D$ decrease is observed for the $3 \perp$ spectrum. It can be explained by the washing out of nonattached to the glass substrate Ag particles together with $\mathrm{AgCl}$ during the fixing process.

Curves $2 / /$ and $3 / /$ behaviors are another. Curve $2 / /$ deep minimum is coinciding virtually by position with the wavelength of the laser beam $(\lambda=445 \mathrm{~nm})$, by which the film was exposed; curve $2 / /$ longwave maximum is weakly manifested, and long-wave gently sloping dispersion is similar to the same of "free solid" Ag film discussed earlier. To some extent, the marked results are in qualitative agreement with the presented in $[2,3]$, wherein artificial anisotropic plasmon $\mathrm{Au}$ structures on waveguide layers were investigated. It is dificult to select and descript the plasmon resonances of $2 / /$ and $3 / /$ curves because of the complex Ag particles distribution in the PS bars (Fig. 2b).

Curve 2// minimum is worthy of notice. The similar minimum has been associated in [2] with at first plasmons excitation in gold nanoparticles distributed periodically on the waveguide layer and then their energy conversion into waveguide mode energy. Note that similar spectral anomalies in AgCl-Ag films transmission spectra were investigated in 1988 [15], i.e., before [2] publication. In [15] the laser beams with different wavelengths were applied to irradiate films and it was shown that peaks of the narrow transmission bands (absorption minima) are coincident by their spectral positions with the applied laser beams wavelengths. These anomalies were explained by the absorption decrease due to $\mathrm{Ag}$ accumulation in the interference minima as the PS develops. Both plasmon and interference mechanism allows 
to explaine spectral drops appearance in the investigated objects absorption.

Both polarizations spectral difference corresponds to linear dichroism, which is related to the PS anisotropy. Note, that after fixing the dichroism (curves $3 / /, \perp$ ) is observed at normal incidence of the measuring beam. As this takes place the PS does not give diffraction at all values $\lambda>445 \mathrm{~nm}$, i.e., in the long-wave part of the investigated spectral range. Therefore, the longwave dichroism should not be attributed to the PS diffraction properties, but only to the light absorption by silver. Before and after fixing the polarized spectra have intersections in which the dichroism is zero. Before fixing the curves intersect at $\lambda=$ $605 \mathrm{~nm}$. Dichroism $\Delta D=D_{\perp}-D_{/ /}$have different signs. Before the fixing a positive dichroism maximum $(\Delta D \approx+0.51)$ is located at $\lambda=460 \mathrm{~nm}$, a negative one increases towards longer wavelengths and reaches a value of $\Delta D \approx-0.37$ at $\lambda=1000 \mathrm{~nm}$. After the fixing the intersection point is strongly shifted to the shorter wavelengths $(\lambda=$ $492 \mathrm{~nm}$ ), the positive dichroism is sharply reduced, and the negative one increases to the value $\Delta D \approx-0.48$ at $\lambda=1000 \mathrm{~nm}$.

Finally, note an important result, which is not shown in Fig. 3 to prevent it from an overload by workpieces. If once more $\mathrm{AgCl}$ film (with a thikness similar to thickness before fixing) is deposited on the fixed sample (spectra $3 \perp / /$ ), the transmission spectra will become similar to spectra $2 \perp$,// again. They differ from the initial in optical density magnitude, but the dispersion behaviors are reproduced adequately by them. In particular, the spectral drop at $\lambda \approx 445 \mathrm{~nm}$ is restored, the spectra intersection point returns about the same $\lambda$ as before the fixing, but $D$ magnitude at this point remains the same as in intersection point of the fixed film spectra. This experiment is an additional proof of the photoinduced PS properties connection with the waveguide $\mathrm{AgCl}$ film properties.

\section{Conclusions}

It has been demonstrated that $\mathrm{AgCl}-\mathrm{Ag}$ thin-film composition has a direct photosensitivity due to localized plasmons excitation in Ag nanoparticles. Waveguide composition properties define the formation of self-tuning consisting of $\mathrm{Ag}$ particles periodical structure under linearly polarized laser beam action. Particles distribution anisotropy leads to the linear dichroism and the appearence of the polarized spectral drop in the absorption spectrum. That can be associated with $\mathrm{Ag}$ accumulation in interference minima at the PS formation process by the laser beam with a given wavelength $\lambda$ and as a result the absorption decreases in its vicinity. On the other hand, the drop may be explained by plasmons excitation in the PS and their energy transfer into waveguide modes energy. It has been shown that the sample fixing leads to the PS conservation. In the process the polarized spectra have been changed significantly, but the dichroism spectral behavior is restored after repeat $\mathrm{AgCl}$ waveguide film deposition on the post-fixing sample.

\section{References}

1. V.V.Klimov, "Nanoplazmonika", Usp. Fiz. Nauk, 178, 875 (2008).

2. S.Linden, J.Kuhl, H.Giessen, Phys.Rev. Lett., 86, 4688 (2001).

3. N.A.Gippius, S.G.Tikhodeyev, A. Krist, et.al., Fiz. Tverd. Tel., 47, 139 (2005)

4. S.G.Tikhodeyev, N.A.Gippius, Usp. Fiz. Nauk, 179, 1003 (2009)

5. L.A.Ageev, V.K.Miloslavsky, Opt. Eng., 34, 960 (1995)

6. V.V.Slutskaja, Tonkie Plenki v Tehnike Sverhvisokih Chastot, Gostehizdat, M.-L. (1962). (in Russian)

7. N.F.Mott and R.W.Gurney, Electronic Processes in Ionic Crystals., Oxford, (1948).

8. M.J.Adams, An Introduction to Optical Waveguides., John Wiley and Sons, N. Y., (1981).

9. M.V.Varminsky, L.A.Ageev, V.K.Miloslavsky. J.Opt., 29, 253 (1998).

10. L.A.Ageev, Y.I.Al-Ashhaab, Zhurn. prikl. spektr.,60, 152, (1994).

11. L.A.Ageev, K.S. Beloshenko E.D. Makovetskiy, V.K. Miloslavsky, Opt. i spektr., 107, 838 (2009).

12. V.N. Zolotarev, V.N. Morozov, E.V. Smirnova Opticheskije Postojannije Prirodnih i Tehnicheskih Sred. Spravochnik, Leningrad Khimiya, (1984) [in Russian].

13. C.F. Bohren, D.R. Huffman, Absorption and scattering of light by small particles, N.Y., John Wiley and Sons, (1982).

14. V.K.Miloslavsky, R.G.Yarovaja, Opt. $i$ spektr., 21, 708 (1966).

15. L.A.Ageev, V.K.Miloslavsky, Nureddin Assaad, Opt. $i$ spectr., 65, 147, (1988). 